\title{
Comunicación y mensajes persuasivos en la promoción de salud y la orientación vocacional.
}

\section{Communication and persuasive messages in health promotion and vocational guidance}

\section{Comunicación y mensajes persuasivos}

\author{
Odalys de la Caridad Pérez Viera PhD ${ }^{(1)}$ \\ Gabriela Sastre Pérez Candidata ${ }^{(2)}$ \\ Norma Placeres Díaz MSC. ${ }^{(3)}$ \\ Amanda León Pérez Lic. Psicología (4)
}

${ }^{1}$ Grupo Psicus. Universidad Reformada Colombia, ORCID. ID 0000-0001-5621-0187

${ }^{2}$ Nova Southeastern University (NSU) Florida Estados Unidos, ORCID. ID 0000-0003-2054-8762

${ }^{3}$ Universidad Tecnológica de La Habana José Antonio Echeverría (CUJAE) Cuba, ORCID. ID 0000-00021326-8968

${ }^{4}$ Facultad de Psicología. Universidad de la Habana (UH) Cuba, ORCID. ID 0000-0002-5331-7859

\section{Resumen}

El trabajo contextualiza elementos esenciales sobre propaganda y publicidad a la labor extensionista de los estudiantes universitarios y trabaja con una muestra de la Universidad Tecnológica de la Habana José Antonio Echeverría (CUJAE), la Universidad de la Habana, la Universidad Reformada de Colombia y la Universidad Autónoma de Santo Domingo. Propone brindar herramientas a partir del análisis y ejemplificación de cómo poder realizarla. En correspondencia, se parte de esclarecer los diferentes tipos de mensajes que pueden brindar: los informativos, los persuasivos y los de recordatorios. Se ponderan los persuasivos y dentro de ellos, las características fundamentales de los mensajes para persuadir. Se complementan estas ideas con las estrategias y técnicas más efectivas de persuasión y un análisis de los compontes del mensaje en cuanto al contenido y la forma. Se finaliza con la evaluación de los atributos del mensaje, a partir de los procesos de atención, percepción y memoria. E incluso que contrarrestan el olvido y posibilitan una mayor recepción de los mensajes por parte de los sujetos que lo reciben.

Palabras clave: Propaganda, publicidad, mensajes persuasivos y extensión universitaria.

\section{Abstract}


The work contextualizes essential elements on propaganda and advertising to the extension work of university students and works with a sample of the Technological University of Havana José Antonio Echeverría (CUJAE), the University of Havana, the Reformed University of Colombia and the Autonomous University of Santo Domingo. It proposes to provide tools based on the analysis and exemplification of how to carry it out. In correspondence, it starts from clarifying the different types of messages they can provide: informative, persuasive and reminders. The persuasive ones are weighed and within them, the fundamental characteristics of the messages to persuade. These ideas are complemented by the most effective strategies and techniques of persuasion and an analysis of the compontes of the message in terms of content and form. It ends with the evaluation of the attributes of the message, based on the processes of attention, perception and memory. And even that they counteract oblivion and enable a greater reception of messages by the subjects who receive it. Keywords: Propaganda, advertising, persuasive messages and university extension.

\section{Introducción}

Una breve historia para introducir el tema

Cierta vez, había un ciego sentado en la vereda con una gorra a sus pies y un pedazo de madera escrito con una tiza blanca que decía: "Por favor ayúdenme, soy ciego". Un publicista que pasaba frente a él se detuvo y observó las pocas monedas que tenía en la gorra. Sin pedirle permiso tomó el cartel, le dio vuelta y con la tiza volvió escribir otro anuncio. Puso nuevamente el pedazo de madera ante los pies del ciego y se marchó.

Por la tarde, el publicista, volvió a pasar frente al ciego que pedía limosna y observó que su gorra estaba llena de billetes y monedas...El Ciego reconoció de inmediato los pasos del hombre y le preguntó si él había sido quien había cambiado su cartel... Y....ante todo ¡¿Qué había escrito?! El publicista respondió: -Nada que no sea tan cierto como tu anuncio, pero, con otras palabras, sonrío y siguió su camino. El nuevo cártel decía: ii Hoy es primavera y no puedo verla...!! ${ }^{1}$

El comenzar con esta historia, obedece a la pretensión de las autoras de motivar y sensibilizar con una apasionante y controvertida temática: la comunicación, la publicidad, la propaganda, los mensajes persuasivos. Comenzar este artículo desde la visión más general de la temática abordada, nos conduce a presentar la comunicación masiva. La comunicación masiva se caracteriza por ser anónima e impersonal, no está dirigida a un individuo en particular, sino a grandes grupos heterogéneos sobre los que es capaz de influir de forma simultánea, a través de medios técnicos (como la prensa, radio, televisión y cine) que son denominados medios de comunicación masiva.

\footnotetext{
${ }_{1}^{1}$ Pérez Viera, O., Bello, M.F. y García, M.R. (2017) Técnicas participativas e historias reflexivas en el proceso de enseñanza-aprendizaje. República Dominicana.
} 
Se caracteriza por tener como fuente una organización formal (institucional) y como emisor un comunicador profesional, que establece una relación unidireccional y pocas veces interactiva con el receptor, que resulta ser parte de una gran audiencia, que reacciona, por lo general, de manera predecible y de acuerdo a patrones ${ }^{2}$.

Por su parte La publicidad, es una técnica de comunicación masiva destinada a difundir mensajes, a través de los medios, con el fin de persuadir a la audiencia al consumo. Busca incidir en el receptor para que tome la decisión de compra en torno al producto o servicio que una organización ofrece. En este sentido, la publicidad es una forma de comunicación, enfocada a incidir en las actitudes de determinado público, para generar un comportamiento de compra o consumo del producto específico que se quiere vender, y que nos parece oportuno trabajar atendiendo al objetivo del presente trabajo.

Pese al sentido comercial con el que a menudo es asociado el concepto, desde la perspectiva de este artículo es analizada la publicidad, como un acto de motivación: Para garantizar su eficacia debe contener elementos que impulsen al receptor a satisfacer las necesidades a las que se enfoca. En consecuencia, no supone solamente la simple "satisfacción de necesidades", sino que debe contener un argumento o motivo y resulta una forma de comunicación de carácter intencional y planificado que tiene en cuenta, para lograr su eficacia, los códigos del receptor.

Los objetivos de la publicidad son: informar, persuadir y convencer. Es decir, incidir sobre las actitudes del receptor. Se trata de estimular el componente emocional de las actitudes, propiciando la tendencia al comportamiento. Desde esta perspectiva, los medios publicitarios, se identifican como los canales o actividades que se utilizan en la publicidad para anunciar servicios o productos ${ }^{3}$. Han sido denominados, también, tradicionalmente como medios de comunicación social y de manera general concebidos como sistemas, formas o vehículos, de que dispone el especialista para hacer llegar a su audiencia blanco los mensajes y anuncios publicitarios.

Dentro de este marco, lo que así denominamos como medios publicitarios, se prestan a servir de vehículo canalizador y difusor de la publicidad. Sin embargo, hay otros medios publicitarios que surgen a partir del auge y desarrollo de esta actividad, como la valla, las marquesinas, los interiores de autobuses, el vestuario de los empleados, etc.

Las técnicas de propaganda, buscan precisamente influenciar y modificar actitudes, creencias, hábitos, dentro de una población o grupo de personas. En el caso que nos ocupa en el presente texto, son los estudiantes universitarios, que deben realizar determinadas labores extensionista entre las que se encuentran: la promoción

\footnotetext{
2 Zayas Agüero, P. M. (2011) La comunicación interpersonal. Un proceso socio-psicológico en el trabajo y en la vida diaria. Editorial Académica Española.

${ }^{3}$ Sotomayor Pereira, J. G.; Brito Gaona L. F. y Teneaca Fajardo, M. A. (2018) Medios publicitarios que influyen en el consumidor a la hora de adquirir un producto o servicio. Revista Killkana Sociales.
} 
de la salud y la orientación vocacional a estudiantes de cursos anteriores, a la que dedicamos especial atención en este material. En este orden de ideas, se mueve nuestro ensayo, que se propone brindar herramientas a los estudiantes universitarios para realizar publicidad en la esfera de extensión universitaria. Estas constituyen necesidades sentidas de los estudiantes, como vía para llegar a la audiencia a que se dirigen y ejercer una influencia en esta. En este caso promover salud y contribuir a la orientación vocacional

\section{Materiales y métodos}

El trabajo se apoyó en el método bibliográfico o de recopilación teórica porque se indagó como sustentación la información relacionada con las variables en fuentes como textos, acuerdos internacionales y los proyectos de similar contenido que existen en las bibliotecas de los centros de Educación Superior, así como el internet. Las fuentes de información que permitieron el respaldo de la presente investigación son de absoluta seguridad la cual se distinguen de la siguiente manera como: Fuentes primarias como revistas científicas (scielo.org redalyc.org, Google Académico, Elsevier), artículos científicos, Organización mundial de la salud (OMS) y Organización Panamericana de la salud (OPS) y; fuentes secundarias como investigaciones ya realizadas por otras instituciones. Para apoyar las herramientas que se pretendían brindar se utilizó la técnica de la encuesta online, y se las realizo con Exel, con 8 preguntas garantizando la calidad de la información la cual fue anónima; el uso de la información fue solo con fines de conocimiento social, informativo y educativo. Se procedió al diseño de una base de datos para realizar el análisis estadístico, se utilizó el programa SPSS. Se estimaron los porcentajes como medida de resumen de la estadística descriptiva y se estimaron las frecuencias relativas. Para analizar los datos estadísticos que se obtuvo del trabajo de campo se utilizó el método analítico que permite explicar e interpretar toda la información cuantitativa. Se realizó grupo focal con un grupo de estudiantes de cursos anteriores para constatar lo planteado por los encuestados. Las autoras declaran no tener conflictos e intereses en el proceso de la investigación; los aspectos éticos estimados en la investigación fueron la discreción en los datos, el manejo de la información y validación de los instrumentos.

\section{Resultados}

Se aplicó la encuesta, utilizando muestro aleatorio simple a 200 entre profesores (100) y estudiantes (100) de las universidades: Universidad Tecnológica de la Habana José Antonio Echeverría (CUJAE), la Universidad de la Habana, la Universidad Reformada de Colombia y la Universidad Autónoma de Santo Domingo. Durante el proceso investigativo, los 200 encuestados plantearon que sí consideran importante se brinden estas herramientas a los estudiantes para su labor extensionista, lo cual es importante en el ámbito de su profesión y de connotado interés profesional con los grupos de estudiantes de cursos anteriores. Sin embargo, fueron interesantes sus propuestas, que incrementaron la selección temática presentada por las autoras y que se incluyen en la proyección presentada en la discusión. 
Válido señalar que los encuestados no ponderan la utilización de la propaganda y los mensajes persuasivos haciendo distinción entre la promoción de la salud y la orientación vocacional. Establecen en igual rango de importancia la utilización en cualquiera de estas labores. Por su parte el grupo focal constata la importancia y valor de estas herramientas para la labor extensionista realizada por ellos.

\section{Discusión}

Los resultados obtenidos avalan la presentación de las herramientas que a continuación exponemos para la labor extensionista de los estudiantes. En este sentido, es oportuno comenzar abordando la tipología de los mensajes.

Existen tres tipos de mensajes: los informativos, los persuasivos y los de recordatorios. Los textos informativos son aquellos que tienen por objetivo transmitir una noticia o conocimiento general acerca de algo. Dentro de este grupo pueden encontrarse tipos de obras muy diferentes entre sí, tales como: noticias, revistas de interés general, artículos enciclopédicos y crónicas periodísticas, entre otros. En general los textos informativos tienen las siguientes características:

- Transmiten un conocimiento acerca de un tema.

- Usan un lenguaje claro y conciso en el desarrollo del contenido.

- Le da cabida, como género mayor, a otros tipos de texto.

- Trata temas variados y se dirige a un público amplio.

Los mensajes de recordatorio hacen acordarse a los consumidores que probablemente necesitan pronto el producto o servicio y dónde encontrarlo; mantiene en su mente un determinado producto.

Los textos persuasivos son de diferente índole, pero todos apuntan a influir en quien los lee o escucha. Este es el tipo de mensaje seleccionado, para su análisis en el trabajo que nos ocupa.

En los textos persuasivos se exponen hechos y argumentos que buscan ilustrar puntos de vista específicos acerca de problemas o situaciones que requieran atención y demostrar por qué hay que tomar decisiones de una manera y no de otra. Con esta ultimo propósito se emplea, en este caso el texto persuasivo, que muchos autores identifican también con un texto argumentativo. La intención es exponer una idea o una serie de razonamientos con la finalidad de lograr convencer al lector, para lo cual, el autor se vale de varios recursos con los que atraer su atención y convencerlo de que su punto de vista es el correcto, para persuadirlo a cambiar su posición, lograr su voto, su preferencia, su inclinación, etc.

Las principales características que se encuentren en los textos argumentativos o persuasivos. 
- Tema: es sobre lo que habla el texto. En este caso la orientación vocacional de los estudiantes y/o la promoción de salud hacia estilos de vida más saludables.

- El objetivo principal de lo que se plantea, es lograr que el receptor se adhiera al pensamiento de quien lo expone.

- Su objetivo principal es lograr brindar las herramientas para elaborar los argumentos para la realización de la labor extensionista universitaria con mayor calidad.

- Tesis: Esta es la parte central de todo texto argumentativo.

- Los argumentos son el cuerpo primario de este tipo de texto. Escribir un argumento es un proceso sistemático que requiere analizar paso a paso las ideas. Los argumentos transmitidos deben girar en torno al tema principal.

- El razonamiento en este contexto se define como la metodología en que el autor presenta sus argumentos.

- Proceso o fases: Está característica hace referencia al orden o estructura en las ideas y los argumentos, neutralizando cualquier rechazo inicial.

- Conclusión: Todo argumento debe contar con una parte que sintetice lo que se ha expuesto en el desarrollo.

Dentro de las características de los mensajes, siguiendo a Casales, JC. (1999) es importante tener en cuenta para persuadir:

- El orden de los argumentos. En correspondencia, si el sujeto está motivado, se utiliza el orden ascendente y si el sujeto no está motivado, el anticlimático, es decir comenzar por argumento más convincente. (La primera fase del proceso persuasivo: es decir hostilidad hacia nuestra posición con impacto inicial, que deben valora los estudiantes mediante la observación y conversación con el público al que está destinado).

- Presentación de conclusiones o no: La presentación de conclusiones lo hace más claro, pero puede generar sentimientos negativos en el receptor y sentirse manipulado, sobre todo en el caso de adolescentes, que es a quienes va dirigido.

- Unilateralidad o bilateralidad de la argumentación: Cuando el nivel cultural es más elevado, presentar todos los argumentos (positivos y negativos) y si el nivel cultural es menos elevado, presentar sólo los positivos. En este caso al tratarse de estudiantes pre-universitarios que aspiran al nivel superior de enseñanza, se puede deducir que como generalidad presenta un nivel cultural de mediano a alto y por tanto se pueden utilizar ambos argumentos. 
- Naturaleza emocional y racional de los argumentos: es importante no abusar de los elementos emocionales (que son muy importantes para persuadir) sobre todo en el nivel cultural alto. En este caso, apelar a la emoción es tratar de asociar un determinado objeto con algo agradable, de manera que luego ese objeto sea capaz, por sí sólo, de evocar esos mismos sentimientos. Es lo que se conoce con el nombre de condicionamiento clásico. Se pueden asociar a las múltiples ventajas que ofrece el sistema educativo universitario, o la promoción de un estilo de vida saludable.

- Argumentos atemorizantes: Depende de la persona, pero se hace mayor resistencia a la persuasión cuando son muy grandes. De manera que es preferible no optar por ellos, aunque en este caso la explicación puede hacer referencia a las consecuencias de una mala elección profesional, con ejemplos cercanos a la realidad de los jóvenes pues es conocido que se pueden dar cambios de carreras, frustración, desilusión, desmotivación. En el caso de las adicciones dentro de las consecuencias si comenzamos por las más drásticas provocara rompimiento por ser tan fuerte el mensaje.

- Cantidad de cambio: Ante posiciones poco radicales más grandes modificaciones en la persuasión y ante rechazo grande, la persuasión debe ser la más moderada. Esto igual dependería de la observación e intercambio inicial con los estudiantes.

Dentro de las técnicas y estrategias más efectivas que pueden ser utilizadas, se encuentran:

- Generalidades brillantes o palabras mágicas: movilizar lo emotivo, lo culturalmente aceptado a partir del uso de palabras o frases convencionalmente favorecedoras.

- Simplificación: para los adolescentes es más favorable presentar el tema de forma simple, para que no resulte tedioso y pierdan el interés.

- Selección de hechos: utilizar hechos que favorezcan puntos de vista propios aportando los que contradicen el criterio de las fuentes.

Dentro de las técnicas de persuasión se encuentran:

\section{Anécdotas, historias y metáforas}

- Las historias son utilizadas desde hace miles de años como vehículo de educación y de persuasión. Éstas suscitan emoción, crean imágenes y delimitan la reflexión crítica...es utilizada cuando se señala

\section{Doble opción $=$ sujeción}

- Ofrecer alternativas expuestas con precaución. Este tipo de cuestiones que encierran al receptor en la lógica del emisor pueden tener una eficacia formidable. Este método conduce al receptor a aceptar o a refutar en su impulso las dos ideas al mismo tiempo.

\section{Encadenar opciones}


- Enlazar los argumentos o ideas unas con otras, por ejemplo:

... "La Universidad Tecnológica de la Habana José Antonio Echeverría (CUJAE) abre sus puertas todos los años para recibir un nuevo grupo de estudiantes ¿Cómo ocurre este proceso? Pues inicia en el nivel en el que se encuentran ustedes ahora...

\section{El beneficio, información, relación}

- La persuasión entra mejor cuando se crea cierta afinidad entre el "persuasor" y su sujeto. Existen varias técnicas a este efecto como, por ejemplo, la introducción positiva ("queridos amigos míos"), o mostrar respeto por el sujeto (sincero o calculado), o incluso hablar la lengua del oyente como es el caso que se utiliza aquí. En este caso, también se puede valer de argumentos que se sabe van a agradar al receptor.

\section{La autoridad}

- Es la autoridad la que por ejemplo hace funcionar el efecto placebo.

\section{Los términos emocionales}

- Ciertas palabras conducen a asociaciones particulares y a emociones positivas o negativas (si bien no todos reaccionan necesariamente de la misma manera). Sin embargo, ciertos términos tienen efectos semejantes. Esta emoción conduce a suspender la reflexión crítica: ¡Peligro!

\section{La conducción}

- El objeto de la conducción consiste en llevar al "sujeto" hacia el objetivo del "persuasor". Esto empieza con una premisa válida y probable. Si el sujeto la acepta, ha pasado la primera etapa: auditorio.

\section{Las cuestiones}

- ...ayudan a hacer aparecer el objetivo del persuasor como una idea del sujeto mismo. En este caso pudiera decirse. “¿Qué hacer entonces? ¿Cómo puedo optar por el estudio en esta institución? ¿Cómo puedo acercarme a los programas de promoción de promoción de salud?"

\section{Las palabras ausentes}

Crear una frase que porta sólo una parte de una alternativa. El mecanismo es poco conocido pero este método parece bastante eficaz, quizás porque da un punto de referencia implícito y lo revaloriza a través de diversos adjetivos o sustantivos ("claro", "evidente", "cierto"...)

\section{Los absolutos}


Una "persona" vulnerable será captada por los absolutos ("siempre", "jamás") que proponen una finalidad destruyendo toda posibilidad de debate. Los términos "deben" o "no deben" implican igualmente una especie de absolutismo.

\section{De lo general a lo particular y viceversa}

De esta manera encontramos se puede partir de una valoración general de la institución universitaria, para luego caracterizar las carreras, o viceversa.

Resulta válido también, realizar el análisis de los compontes del mensaje en cuanto al contenido y la forma.

En el contenido se expresa la intención explícita del mensaje, qué se ofrece y qué satisface. Por tanto, expresa atributos diferenciadores del producto que sean significativos y movilizadores para el sujeto. Se trabaja con estereotipos, significados, representaciones, valores que maneja el receptor.

La forma es un vehículo para garantizar la recepción eficaz del mensaje, se subordina a este; no es vista desde un punto de vista artístico, sino funcional. Es la combinación óptima de los elementos gráficos y de texto para la transmisión efectiva del mensaje.

$\mathrm{Y}$ es que, desde el punto de vista gráfico, se deben tener consideraciones de tipo perceptual que garanticen la visibilidad de este. Hacer uso de texto, imagen y sonido en aquellos momentos que corresponda, o sea, se debe buscar la forma óptima de comunicar determinado mensaje.

Para hacer eficaz un mensaje publicitario es necesario el conocimiento por parte del emisor de los códigos con que "procesa" y se orienta el receptor. Estos códigos pueden ser de carácter formal, o de contenido. La formal que son las reglas de percepción (visuales, en este caso), relativas a propiciar determinada estética, para facilitar la aprehensión del mismo.

En este caso la argumentación, puede ir acompañada de una presentación PowerPoint, un video de formación vocacional, videos que ilustren la labor de los jóvenes en el centro, los festivales de cultura, las graduaciones, que además de motivar por el mensaje, harán que su retención se realice con mayor facilidad.

\section{Evaluación de los atributos del mensaje a partir de los procesos atención. Percepción y memoria}

Atributos del mensaje relacionados con la atención

- Prepotencia o intensidad: unos estímulos son más fuertes que otros, más potentes y así suelen ganar rápidamente la atención. Los colores fuertes lo son ante los colores pasteles, los sonidos fuertes ante los débiles. 
- Cambio: movimiento en cualquier dirección, de un lugar a otro, de un tono a otro. Aquellos mensajes que empelan imágenes que sugieren movimiento ganan mejor la atención que aquellos que aluden inmovilidad.

- Tamaño: generalmente lo grande atrae mejor la atención, aunque el valor de la atención no es directamente proporcional al tamaño. De igual forma, entre objetos grandes uno pequeño puede ganar rápido la atención.

- Repetición: un estímulo débilmente repetido puede ser tan eficiente como un estímulo fuerte que se da una sola vez. Por otro parte, el uso desproporcionado de la repetición puede traer monotonía y ante ello, el sujeto rechaza el contacto con el mensaje.

Atributos del mensaje relacionados con la percepción

- Semejanza: cuando se emplean elementos semejantes da coherencia y sirve para reafirmar el mensaje. (gestalt).

- Contraste figura- fondo: la figura es el elemento principal. De no ser adecuadamente escogido el fondo, en este se pierde la figura y deja de ser eficiente.

- Proximidad: los elementos que componen un mensaje deben guardar determinado acercamiento físico entre ellos, ya que esto le imprime armonía y también congruencia.

- Uso del color. Principios básicos de aplicación del color:

a) Coherencia entre el contenido y la forma: el empleo del color es adecuado al carácter e intención del mensaje, teniendo en cuenta las diferentes reacciones emotivas y afectivas de los receptores, así como su simbolismo a través del uso de la luminosidad o distintos tonos.

Memoria. Leyes que hacen posible que el mensaje no se olvide.

- Ley de la repetición (ley del ejercicio): cuanto más frecuente se vean y oigan los mensajes, más se recordarán. Los intervalos entre repeticiones deben ser más bien amplios ( 2 al día, por ejemplo). Para utilizar de manera correcta esta ley es necesario tener en cuenta las siguientes reglas:

a) Repetir sin llegar a la saturación del lector, evitando la monotonía y el cansancio.

b) Repetir introduciendo algunas ligeras modificaciones que no alteren la esencia y contenido del men saje, es decir, solo en su forma de presentación.

- Ley de la primacía: lo que se ve primero se recuerda mejor. Aquellas conexiones que han sido establecidas con anterioridad, tienen ventaja sobre las demás, ya que hay posibilidad de recordarlas primero. 
- Ley de lo más reciente: se recuerda mejor lo último que vemos.

- Ley del efecto: una experiencia que produzca un efecto agradable, queda más fácilmente fijada en la memoria que otra que produzca un efecto desagradable, esta última tiende a ser olvidada, y aún más, las experiencias que producen efectos agradables o desagradables son más fácilmente recordadas que las neutras.

- Ley del interés: cuando tenemos interés en algo recordamos mejor. Si se apela al interés, motivos y deseos de los receptores el mensaje se fijará mejor y se olvidará menos.

\section{Aspectos que ayudan a contrarrestar el olvido del mensaje.}

1- Las imágenes visuales se recuerdan más que las auditivas

2- Los textos cortos son mejor recordados que los extensos conformados por varias frases.

3- Los mensajes que apelan al interés y a la motivación del público son menos olvidados.

4- La utilización de la narrativa facilita el recuerdo de la publicidad, ya que debidamente empelada proporciona una lectura más interesante y amena. Así se narra lo encontrado en los estudios científicos

Soporte y espacio.

Se llama soporte, dentro de un medio genérico, a los distintos periódicos, emisoras, canales, etc. (Ej: dentro de la prensa escrita o plana, el soporte serían los periódicos y revistas; si nos refiriéramos al medio radial, serían sus diferentes emisoras, etc.). En este caso la labor de extensión universitaria vinculada a tareas como la orientación vocacional y la promoción de salud en estudiantes pre-universitarios, pueden apoyarse de espacios virtuales que ya existen como las revistas, las páginas, en redes sociales de frecuente uso: Telegram, Instagram, Facebook, grupos de WhatsApp como canales para socializar información de un modo más actual y cercano, de manera que crezca su interés por apropiarse del mensaje.

\section{Conclusiones}

El presente trabajo nos ha permitido contextualizar la propaganda y la publicidad en función de necesidades comunicativas de los estudiantes de la universidad para hacer su labor extensionista de orientación vocacional y la promoción de salud de los estudiantes de cursos anteriores. Hacer un análisis de la propaganda como técnica de la comunicación masiva y permite arribar a las siguientes conclusiones

Resulta esencial para los estudiantes universitarios, dentro su labor extensionista en el entrenamiento, la elaboración de mensajes informativos de tipos recordatorios, pero sobre todo persuasivos, que en este caso se 
distinguen por utilizar argumentos racionales y emocionales, bilateralidad de los mismos y ofrecer conclusiones sin declararlas explícitamente.

Utiliza técnicas de persuasión y estrategias que apuestan por la comprensión y motivación de los adolescentes a los que va dirigido, elaborar el mensaje atendiendo a los procesos cognitivos de atención percepción y memoria. Brinda la posibilidad de incursionar en un análisis que favorezca la recepción más efectiva del mismo, en la labor de orientación vocacional y de promoción de salud, como uno de las actividades extensionistas que realizan los estudiantes universitarios.

Utilizar medios actuales y motivadores como las redes sociales, debido al impacto que tienen en la actualidad y en la población adolescente y joven, puede garantizar que el mensaje tenga mayor receptibilidad y eficacia.

\section{Bibliografía}

1. Aprile. Orlando C. (2000) La Publicidad estratégica. Estudios de Comunicación. Editorial Paidós, Buenos Aires.

2. Casales Julio C. (1999) Psicología Social. Editorial Pueblo y Educación. La Habana.

3. Examples of Different Kinds of Persuasion in Advertising. Recuperado el 21 de septiembre de 2017, de smallbusiness.cron.com

4. Sotomayor Pereira, J. G.; Brito Gaona L. F. y Teneaca Fajardo, M. A. (2018) Medios publicitarios que influyen en el consumidor a la hora de adquirir un producto o servicio. Revista Killkana Sociales.

5. Pérez Viera, O., Bello, M.F. y García, M.R. (2017) Técnicas participativas e historias reflexivas en el proceso de enseñanza-aprendizaje. República Dominicana.

6. Zayas Agüero, P. M. (2011) La comunicación interpersonal. Un proceso socio-psicológico en el trabajo y en la vida diaria. Editorial Académica Española. 